\section{Pacific Northwest}

National Laboratory

Operated by Battelle for the

U.S. Department of Energy

\title{
Non-Process Element (NPE) Removal Using Functionalized Monolayers on Mesoporous Supports
}

\author{
R. K. Leugemors \\ S. V. Mattigod \\ G. E. Fryxell \\ W. H. Persinger
}

March 2004

\author{
Prepared for the U.S. Department of Energy \\ under Contract DE-AC06-76RL01830
}




\title{
DISCLAIMER
}

This report was prepared as an account of work sponsored by an agency of the United States Government. Neither the United States Government nor any agency thereof, nor Battelle Memorial Institute, nor any of their employees, makes any warranty, express or implied, or assumes any legal liability or responsibility for the accuracy, completeness, or usefulness of any information, apparatus, product, or process disclosed, or represents that its use would not infringe privately owned rights. Reference herein to any specific commercial product, process, or service by trade name, trademark, manufacturer, or otherwise does not necessarily constitute or imply its endorsement, recommendation, or favoring by the United States Government or any agency thereof, or Battelle Memorial Institute. The views and opinions of authors expressed herein do not necessarily state or reflect those of the United States Government or any agency thereof.

\author{
PACIFIC NORTHWEST NATIONAL LABORATORY \\ operated by \\ BATTELLE \\ for the \\ UNITED STATES DEPARTMENT OF ENERGY \\ under Contract DE-AC06-76RL01830
}

This document was printed on recycled paper. 


\section{Non-Process Element (NPE) Removal Using Functionalized Monolayers on Mesoporous Supports}
R. K. Leugemors
S. V. Mattigod
G. E. Fryxell
W. H. Persinger ${ }^{(a)}$

March 2004

Prepared for

the U.S. Department of Energy

under Contract DE-AC06-76RL01830

Pacific Northwest National Laboratory

Richland, Washington 99352

(a) Weyerhaeuser 


\section{Summary}

As Kraft pulp mills move toward minimum impact manufacturing, one of the most difficult challenges is the development of strategies for dealing effectively with buildup, carryover, and recovery of cationic and anionic non-process elements (NPEs). Even at low concentrations, NPEs present a serious concern due to scaling and other reactions caused by $\mathrm{Ca}, \mathrm{Mg}, \mathrm{Mn}, \mathrm{Fe}, \mathrm{Cu}$, phosphates, silicates, and aluminates. The drivers behind NPE removal include environmental regulatory issues (e.g., Mn), scale formation, reduced bleaching efficiency, and corrosion. Before closure can be achieved in the bleach cycle (Figure 1), methods must be developed for efficient and cost-effective removal of NPEs from bleach filtrate streams. To be commercially viable, a highly selective, high-capacity, and regenerable media must be developed. In addition, limited prefiltration and high resistance to attrition of exchange material will significantly reduce costs, which is key to widespread commercial application.

This project accurately determined the chemical composition of a Weyerhauser bleach plant effluent in the $E_{\text {op }}, D_{0}$, and $D_{1}$ stages. Due to environmental regulatory concerns, Mn was the principal target of this study. Mn was found to be present in these samples in the range of 0.16 to $3.97 \mathrm{ppm}$. The Mn was found to be in the divalent oxidation state. Other species of interest were the scale forming cations Ca (21.4 to $161 \mathrm{ppm}$ ) and $\mathrm{Mg}$ (1.0 to $20 \mathrm{ppm}$ ); Ba is not likely to be a significant cause of scale in these effluents and is present only in the range of 0.03 to $0.22 \mathrm{ppm}$. Various methods were evaluated for their ability to remove $\mathrm{Mn}^{+2}$ from these effluents, and carboxylate Self-Assembled Monolayers on mesoporous supports (SAMMS) was found to be the most effective sorbent tested.

To be able to deploy SAMMS in an industrial setting, it was necessary to design a process scheme that would allow suitable flow rates with minimal back pressures. This process design was drawn up and incorporated into a truck-portable skid that could be dropped in place and plumbed into the bleach plant for pilot-scale testing and evaluation. Critical issues for the successful application of SAMMS in this upflow fluidized bed (UFFB) system were settling velocity and particle size attrition, so these measurements were made. Attrition was found to generate fines $(<53 \mu \mathrm{m})$ up to approximately $6 \mathrm{wt} \%$, and then fines generation leveled off. The settling velocity testing showed that with appropriate system design and fines recovery, the SAMMS material could be used in the UFFB system.

Extensive testing was carried out to find which functional groups were most effective to bind the scale-forming cations under conditions similar to those encountered in the pulp bleaching process. The sulfonate resin was found to be the most effective overall, except for removing Ca from the alkaline $\mathrm{E}_{\mathrm{op}}$. The diphosphonate was found to be the second most effective overall, but it tended to lose its efficacy at higher solution-to-solid ratios. The carboxylate was effective at removing $\mathrm{Ca}$ and $\mathrm{Mg}$, but not as effective at removing $\mathrm{Ba}$ (which is acceptable since $\mathrm{Ba}$ is the smallest concern in these effluents). The phosphonate resin was found to be very effective at removing $\mathrm{Mg}$ under both acidic and alkaline conditions, very good at removing Ca at pH 2.5 and 7.5, but basically ineffective at more acidic pHs.

Tests were carried out to evaluate the sorption kinetics of SAMMS materials for scale-forming cations. Sorption was rapid, and equilibrium was achieved in just a few minutes. Once sorbed, there was no evidence of Ca leaching back out of the SAMMS sorbent material. 


\section{Contents}

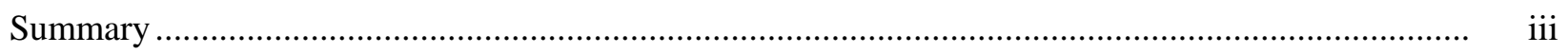

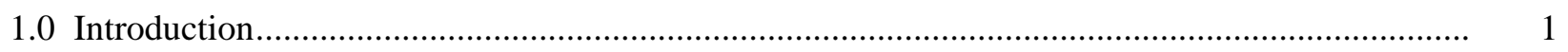

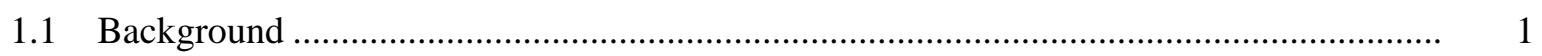

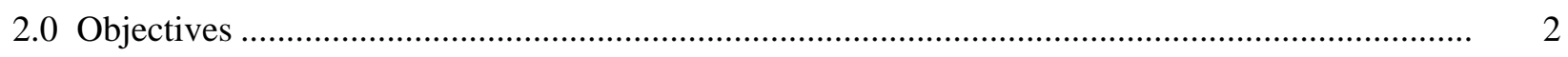

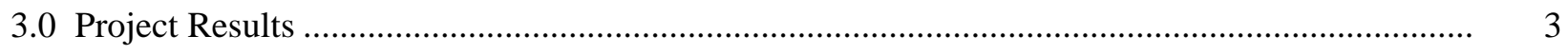

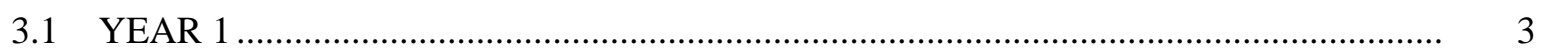

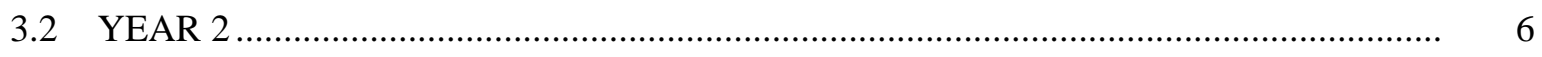

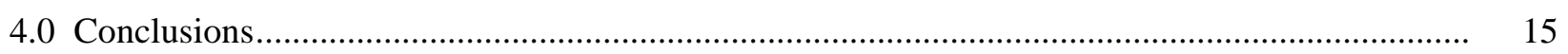

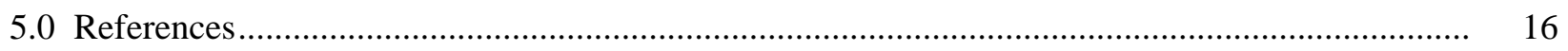

Appendix 1 - Oglethorpe Waste Composition ....................................................................... A.1

\section{Figures}

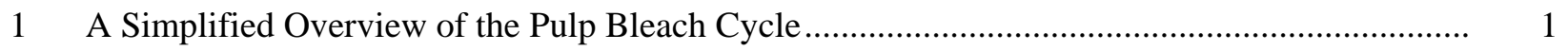

2 Self-Assembled Monolayers on Mesoporous Supports......................................................... 2

3 Synthesis of Glycinyl Urea Silane ..................................................................................

$4 \quad$ Glycinyl Urea SAMMS Chelating Mn(II) ....................................................................

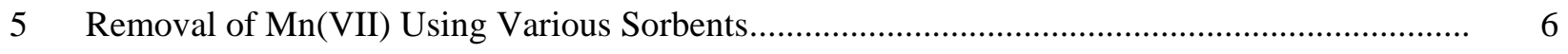

6 Schematic of UFFB System for Deployment of SAMMS …................................................ 8

$7 \quad$ Calibration Curve: Turbidity Versus Total Suspended Solids .............................................. 9

$8 \quad$ TSS in the Effluent as a Function of Flow Rate .................................................................... 10 
$9 \quad$ Attrition of Thiol-SAMMS as a Function of Time................................................................ 10

10 Attrition Test of Thiol-SAMMS as a Function of Time.......................................................... 11

11 Synthetic Approaches Used to Make Various Functionalities on SAMMS ............................... 12

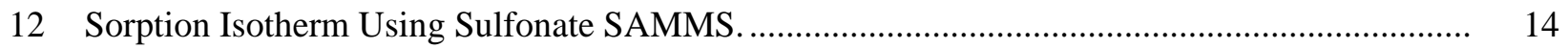

13 Sorption Kinetics of Ca Using Sulfonate SAMMS................................................................ 14

\section{Tables}

1 Chemical Characteristics of Effluents from the Bleach Process.................................................. 4

2 Distribution Coefficients for Ca Using Sulfonate SAMMS ................................................... 13 


\subsection{Introduction}

The research area for this work is Environmental Performance - Technologies for Conditioning or Treating In-Process Water Streams or Wastewaters to Make Them Suitable for Reuse in the Mill.

\subsection{Background}

Closing the Bleach Cycle. As Kraft pulp mills move toward minimum impact manufacturing, one of the most difficult challenges is the development of strategies for dealing effectively with buildup, carryover, and recovery of cationic and anionic non-process elements (NPEs). Even at low concentrations, NPEs present a serious concern due to scaling and other reactions caused by $\mathrm{Ca}, \mathrm{Mg}, \mathrm{Mn}, \mathrm{Fe}$, $\mathrm{Cu}$, phosphates, silicates, and aluminates. The drivers behind NPE removal include environmental regulatory issues (e.g., $\mathrm{Mn}$ ), scale formation, reduced bleaching efficiency, and corrosion. Before closure can be achieved in the bleach cycle (Figure 1), methods must be developed for efficient and cost-effective removal of NPEs from bleach filtrate streams. To be commercially viable, a highly selective, highcapacity, and regenerable media must be developed. In addition, limited prefiltration and high resistance to attrition of exchange material will significantly reduce costs, which is key to widespread commercial application.

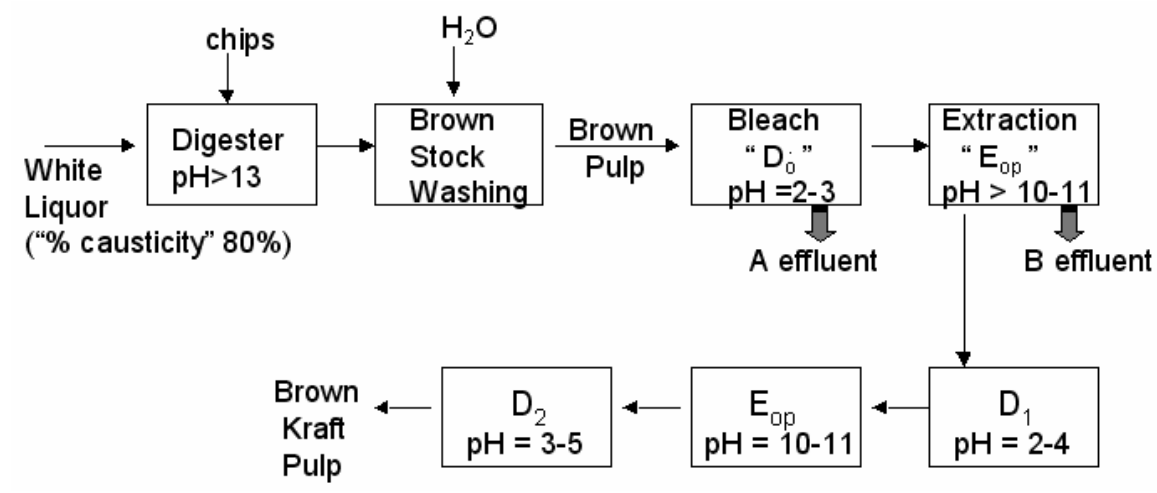

Figure 1. A Simplified Overview of the Pulp Bleach Cycle

The drivers for NPE removal from the bleach plant effluent include environmental regulatory issues, reduction (or elimination) of scale formation, enhanced bleaching efficiency, and reduction (or elimination) of chloride-induced corrosion. A suitable chemical separation technology to remove these NPEs could potentially address all of these issues.

SAMMS Application to the Bleach Plant Effluent. A powerful new class of environmental sorbent material has been developed at Pacific Northwest National Laboratory (PNNL), called Self-Assembled Monolayers on Mesoporous Supports (SAMMS) (Figure 2). The advantages of SAMMS include high sorbent capacity as a result of the high surface area of the support, the rapid sorption kinetics resulting from the rigid, open-pore structure of the support, the chemical specificity of the monolayer interface, and the ability to tailor the chemical specificity of the sorbent by varying the monolayer composition. Once 
the composition of the bleach plant effluent was well characterized, it was possible to design SAMMS materials for specific target NPEs and evaluate their efficacy at removal of these targets.

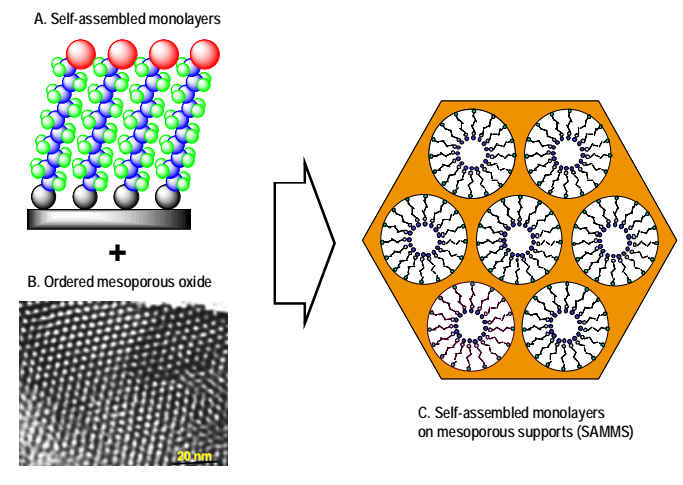

Figure 2. Self-Assembled Monolayers on Mesoporous Supports (SAMMS)

SAMMS are made by using surfactant micelles as templates to make a porous, honeycombed ceramic support, which condenses a huge amount of surface area into a very small volume. This support is then decorated with a self-assembled monolayer containing a suitable terminal ligand to bind the target analyte. By varying the chemical structure of the monolayer interface, the SAMMS sorbent materials can be tailored to be specific for a wide variety of targets.

\subsection{Objectives}

The objective of the development phase of this project was to generate performance data sufficient to enable SAMMS to be commercially deployed for the removal of problematic NPEs. The project obtained data on the composition of bleach plant effluent, performed preliminary evaluation of sorbent functionality using commercial ion-exchange resins on the target NPEs, and designed, synthesized, and evaluated SAMMS with the down-selected functionality to target specific NPEs through pilot-scale demonstration of the removal of alkaline earth metals.

The test plan included:

1. Physical Characterization of SAMMS Material. The characteristics that are critical for deploying SAMMS materials in a fluidized bed column are the settling velocity and attrition resistance. Benchscale tests were conducted for the range of scaled flow rates that would be used in the pilot-scale operation. Additionally, we conducted attrition tests on SAMMS material. Changes in particle size distribution as a function of agitation time were measured to assess the attrition resistance of the material.

2. Functionality Selection Tests. The objective of these tests was to identify functionalities that specifically remove scale-forming alkaline earth metals from bleach effluent streams. We assessed the performance of several commercially available functionalities on resin substrates. A promising functional group is the chelating iminodicarboxylic acid via methodology developed at PNNL. This chelating iminodicarboxylic acid interface has a high affinity for scale-forming cations such as $\mathrm{Ca}$ 
and Mg, and transition metal cations such as Mn. The chelating iminodicarboxylic acid in SAMMS is strippable, and hence regenerable. These bench-scale tests were conducted in a batch mode with simulants to determine the selectivity, loading, and kinetics of adsorption.

3. Flow and Regeneration Tests. Bench-scale tests, using simulants, were performed to evaluate loading and regeneration performance of functionalities selected from the results of the screening tests.

4. Batch and Flow Tests of Functionalized SAMMS. A series of tests with actual bleach cycle effluents was conducted to determine the effectiveness of functionalized SAMMS material for alkaline earth metal removal. The tests were focused on measurements of selectivity, loading, kinetics, and regeneration properties of the SAMMS material.

\subsection{Project Results}

\subsection{YEAR 1}

The research focus in Year 1 was to determine the accurate composition of the bleach plant effluent sample we were provided, particularly on the Mn speciation, and to evaluate SAMMS as a possible means of Mn removal.

Bleach Plant Effluent Characterization. During the first year of the project, PNNL performed a detailed effluent stream characterization of three different stages $\left(D_{0}, D_{1}\right.$, and $\left.E_{o p}\right)$ of the bleach cycle (Table 1). This was a significant scope of work that included not only the determination of constituent concentrations but also a determination of the specific valance states for the NPEs of concern. The research results showed that:

1. Principal scale-forming constituents in these effluents were Ca, oxalate, sulfate, and carbonate.

2. Concentrations of transition metals such as $\mathrm{Co}, \mathrm{Cu}, \mathrm{Cr}, \mathrm{Fe}$, and $\mathrm{Zn}$ in these samples were $\sim 0.1 \mathrm{mg} / \mathrm{L}$.

3. Measurable concentrations of Mn were found in all three effluents $\left(D_{0}: \sim 4 \mathrm{mg} / \mathrm{L}, \mathrm{D}_{1}: 0.5 \mathrm{mg} / \mathrm{L}\right.$, and $\left.\mathrm{E}_{\mathrm{op}}: 0.2 \mathrm{mg} / \mathrm{L}\right)$.

4. $\mathrm{Mn}$ in the $\mathrm{D}_{0}$ and $\mathrm{D}_{1}$ samples was determined to be in a divalent oxidation state.

5. Mn adsorption tests using simulants as well as actual $D_{0}, D_{1}$, and $E_{o p}$ effluent samples indicated that glycinyl urea SAMMS and Dowex resin were very effective in removing the bulk of dissolved Mn (II) from these effluents. These tests demonstrate that Mn (II) can be effectively removed from all three effluent streams. 
Table 1. Chemical Characteristics of Effluents from the Bleach Process (mg/L)

\begin{tabular}{|c|c|c|c|c|c|c|}
\hline \multirow[b]{2}{*}{ Constituent } & \multicolumn{2}{|c|}{$E_{o p}$} & \multicolumn{2}{|c|}{$\mathrm{D}_{0}$} & \multicolumn{2}{|c|}{$\mathrm{D}_{1}$} \\
\hline & $\mathrm{A}^{(\mathrm{a})}$ & $\mathrm{B}^{(\mathrm{b})}$ & $\mathrm{A}^{(\mathrm{a})}$ & $\mathrm{B}^{(\mathrm{b})}$ & $A^{(a)}$ & $\mathrm{B}^{(\mathrm{b})}$ \\
\hline $\mathrm{Al}$ & 0.36 & 0.29 & 1.32 & 1.16 & 0.49 & 0.52 \\
\hline B & 0.01 & 0.25 & 0.11 & 1.44 & $<0.01$ & 0.88 \\
\hline $\mathrm{Ba}$ & 0.03 & 0.06 & 0.22 & 0.21 & 0.10 & 0.03 \\
\hline $\mathrm{Ca}$ & 35.10 & 21.40 & 161.00 & 146.40 & 36.50 & 34.80 \\
\hline $\mathrm{Cd}$ & $<0.08$ & $<0.08$ & $<0.08$ & $<0.08$ & $<0.08$ & $<0.08$ \\
\hline Co & $<0.03$ & $<0.03$ & 0.03 & $<0.03$ & $<0.03$ & $<0.05$ \\
\hline $\mathrm{Cr}$ & $<0.08$ & $<0.08$ & $<0.08$ & $<0.08$ & $<0.08$ & $<0.08$ \\
\hline $\mathrm{Cu}$ & $<0.01$ & $<0.01$ & $<0.01$ & 0.01 & $<0.01$ & $<0.01$ \\
\hline $\mathrm{Fe}$ & $<0.01$ & $<0.01$ & 0.24 & 0.04 & 0.01 & $<0.01$ \\
\hline K & 2.58 & 0.24 & 12.45 & 12.21 & 0.73 & $<0.24$ \\
\hline $\mathrm{Mg}$ & 3.16 & 1.03 & 20.22 & 18.27 & 9.85 & 9.43 \\
\hline $\mathrm{Mn}$ & 0.23 & 0.16 & 3.97 & 3.07 & 0.30 & 0.51 \\
\hline Mo & $<0.05$ & $<0.05$ & $<0.05$ & $<0.05$ & $<0.05$ & $<0.05$ \\
\hline $\mathrm{Na}$ & 1494.10 & 1417.70 & 273.70 & 249.60 & 936.00 & 906.90 \\
\hline $\mathrm{Ni}$ & $<0.10$ & $<0.10$ & $<0.10$ & $<0.10$ & $<0.10$ & $<0.10$ \\
\hline $\mathrm{Pb}$ & $<0.08$ & $<0.08$ & $<0.08$ & $<0.08$ & $<0.08$ & $<0.08$ \\
\hline Si & 6.23 & 5.58 & 7.02 & 3.72 & 3.18 & 3.63 \\
\hline $\mathrm{Sr}$ & 0.03 & 0.02 & 0.28 & 0.24 & 0.07 & 0.06 \\
\hline Zn & $<0.05$ & 0.11 & 0.33 & 0.99 & 0.13 & 0.83 \\
\hline $\mathrm{F}^{-}$ & 19.20 & -- & 4.30 & -- & 7.08 & -- \\
\hline $\mathrm{Cl}^{-}$ & 277.00 & -- & 585.00 & -- & 285.00 & -- \\
\hline $\mathrm{ClO}_{3}$ & 92.20 & -- & 320.00 & -- & 144.00 & -- \\
\hline $\mathrm{CHO}_{2}$ & 80.70 & -- & 10.10 & -- & 0.64 & -- \\
\hline $\mathrm{CO}_{3}$ & 356.70 & -- & -- & -- & -- & -- \\
\hline $\mathrm{C}_{2} \mathrm{O}_{4}$ & 102.00 & -- & 11.00 & -- & 19.40 & -- \\
\hline $\mathrm{Br}^{-}$ & 0.05 & -- & $<0.05$ & -- & 0.06 & -- \\
\hline $\mathrm{NO}_{3}^{-}$ & 5.16 & -- & 19.50 & -- & 2.49 & -- \\
\hline $\mathrm{PO}_{4}$ & $<0.50$ & -- & 6.08 & -- & 0.71 & -- \\
\hline $\mathrm{SO}_{3}$ & $<0.50$ & -- & 7.05 & -- & 0.96 & -- \\
\hline $\mathrm{SO}_{4}$ & 157.00 & -- & 123.00 & -- & 780.00 & -- \\
\hline pH (SU) & 10.95 & 10.30 & 2.07 & 2.12 & 4.40 & 4.42 \\
\hline $\begin{array}{l}\text { (a) } 0.45 \mu \mathrm{m} \\
\text { (b) } 20 \mathrm{~A} \text { fil }\end{array}$ & & & & & & \\
\hline
\end{tabular}


Mn(II) Removal. Mn(II) removal tests included an activated alumina (Alcan AA-101), a highsurface-area silica (MCM-41), Dowex resin, and three varieties of SAMMS (carboxylate, phosphonate and sulfonate SAMMS [Figure 3]). These studies were carried out over a range of $\mathrm{pH}$ values ranging from 1.8 to 10.0, using a solution-to-solids ratio ranging from 20 to 5000 (500 is typical for SAMMS). The Mn (II) concentration was varied from 0.3 to $35 \mathrm{ppm}$, and contact times were 6 - 8 hours to ensure that distribution coefficient $\left(\mathrm{K}_{\mathrm{d}}\right)$ values obtained were true equilibrium values (in metal sorption studies, SAMMS typically reach equilibrium in 3-30 minutes depending on concentration, $\mathrm{pH}$, competing complexants, etc.). In summary, these studies found that the acidic SAMMS (as well as the Dowex IX resin) were effective at removing Mn(II). The carboxylate SAMMS was the most effective sorbent tested with a $\mathrm{K}_{\mathrm{d}}$ above 6,000. Not surprisingly, the efficacy of all these sorbents was $\mathrm{pH}$-dependant. The carboxylate SAMMS worked best at a $\mathrm{pH}$ above 5, while the sulfonic acid resins work moderately well at a pH of about 2. The inorganic oxides were found to be completely ineffective at removing Mn(II) (Figure 4).

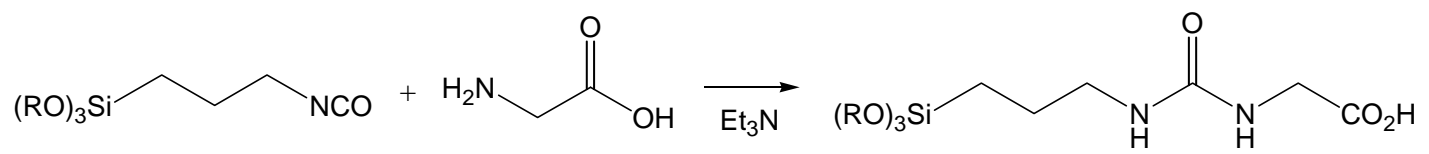

Figure 3. Synthesis of Glycinyl Urea Silane
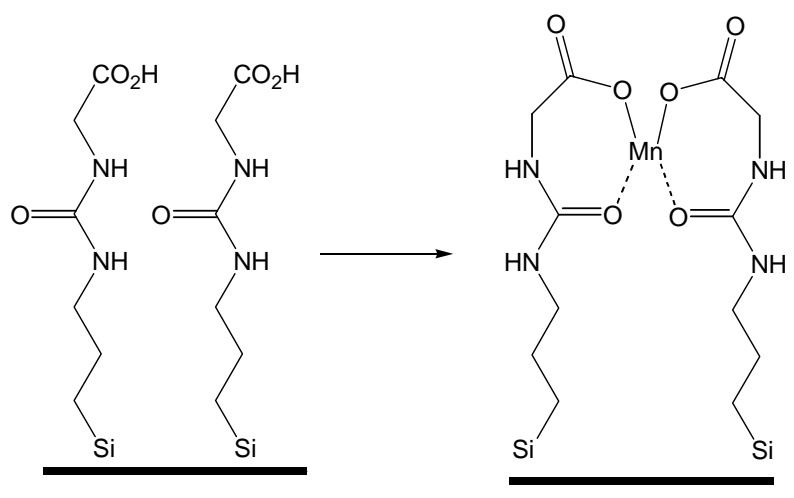

Figure 4. Glycinyl Urea SAMMS Chelating Mn(II)

Mn(VII) Removal. Due to the strongly oxidizing conditions encountered at specific points of the bleaching process, it was postulated that Mn might also be found in the +7 oxidation state at certain points in the bleaching process. Therefore, a series of tests was performed to evaluate how well SAMMS might be able to remove permanganate anion (Figure 5).

$\mathrm{Cu}(\mathrm{EDA}) \mathrm{SAMMS}$ have shown significant affinity for tetrahedral oxometallate anions (Fryxell et al. 1999). As a result, we tested Cu(EDA) SAMMS for its affinity for permanganate anion. When the solution-to-solids ratio was increased from 50 to 10,000, the $K_{d}$ increased from approximately 0 to over 100,000 . This observation strongly suggests that a simple ion-exchange, or chelation, process is not taking place, but rather some redox process is occurring in which the oxidized form of the SAMMS material has a much higher affinity for Mn (in its final oxidation state) than does the starting material. 
The $\mathrm{pH}$ became progressively more alkaline in these treatments. Similar results were obtained for EDA SAMMS, as well as for the ion exchange resin treated with EDA silane.

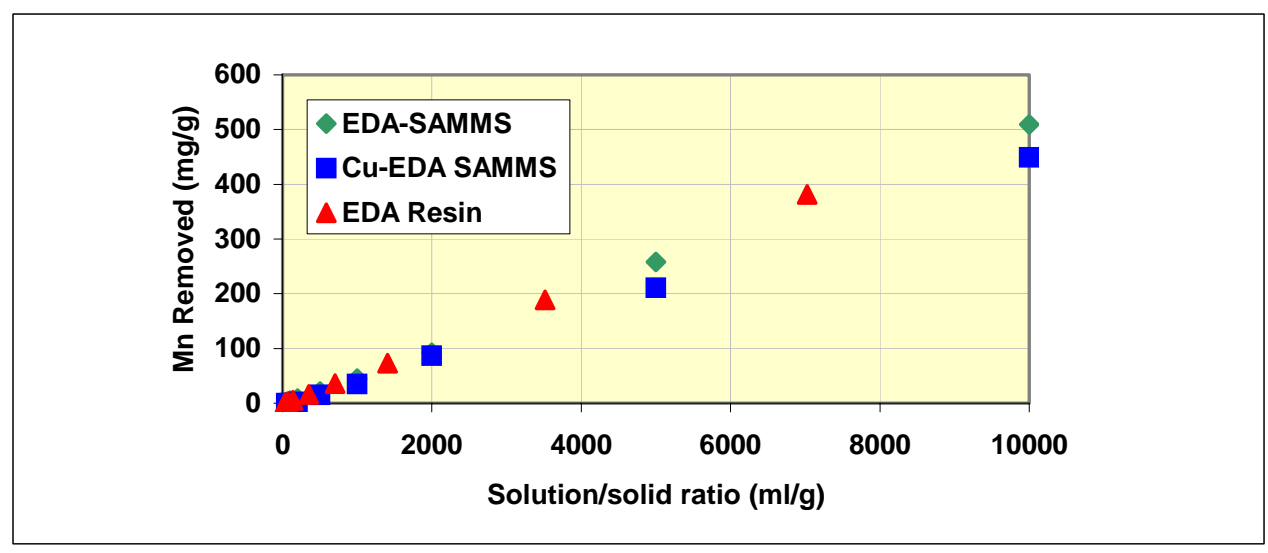

Figure 5. Removal of Mn(VII) Using Various Sorbents

In short, SAMMS were found to be an effective method for Mn(VII) removal, with the probable mechanism being a redox-driven precipitation process. The kinetics of Mn(VII) removal were found to be rapid.

\subsection{YEAR 2}

Suggestions from industry (and a request from the client), led to the scope of this project being shifted in Year 2 from removal of Mn to removal of scale-forming cations, specifically $\mathrm{Ca}, \mathrm{Mg}$, and $\mathrm{Ba}$. In addition, preliminary requirements and design criteria for pilot scale demonstration were addressed.

Functionality Tests. An extensive database was assembled using commercially available ion exchange resins to evaluate which functional groups were most effective at removing the scale-forming cations ( $\mathrm{Ca}, \mathrm{Mg}$, and $\mathrm{Ba}$ ) under conditions similar to those experienced in the pulp bleaching process. The resins tested included Sybron IONAC SR-12 (a diphosphonate resin with $1.6 \mathrm{meq} / \mathrm{ml}$ ), Bayer Lewatit CNP80WS (a carboxylate resin with $4.3 \mathrm{meq} / \mathrm{mL}$ ), Biorad AG 50W-X12 (a sulfonate resin with 2.1 $\mathrm{meq} / \mathrm{mL}$ ), and Resintech SIR-500 (an aminophosphonate resin with $1.4 \mathrm{meq} / \mathrm{mL}$ ). These resins were tested at pHs of 1.8, 2.5, 7.5, and 10.0 (the acidic $\mathrm{pH}$ samples were taken from the $\mathrm{D}_{0}$ and $\mathrm{D}_{1}$ stages, the alkaline samples were taken from the $\mathrm{E}_{\mathrm{op}}$ stage, and the near-neutral $\mathrm{pH}$ was taken from a mixture of the $E_{\text {op }}: D_{0}: D_{1}$ in the ratio of 3:1:1). The solution-to-solid ratio varied from 50 to 500 .

Mg was removed very effectively by all 4 resins under alkaline conditions at all solution-to-solid ratios (>95\% Mg removed, with the exception of the Biorad sulfonate at a solution-to-solid ratio of 500, which only removed $85 \%$ of the $\mathrm{Mg}$ ). Under alkaline conditions, Ca removal was found to be not nearly as effective. The only conditions that were above $90 \%$ Ca removal were the Resintech aminophosphonate at a solution-to-solid ratio of 100 and the Bayer carboxylate at a solution-to-solid ratio of 500 (all the rest were considerably lower). 
The $\mathrm{pH} 1.8$ samples (i.e., $\mathrm{D}_{0}$ ), $\mathrm{Mg}$ removal tended to be very good (90-99\%) at solution to solid ratios of 50-100, but they fell off markedly (50-80, and some even lower) at a solution-to-solid ratio of 500. Ca removal at $\mathrm{pH} 1.8$ was similar, with the exception that the Biorad sulfonate maintained its effectiveness at a solution-to-solid ratio of 500 ( $>95 \%$ Ca removal). Ba removal at this $\mathrm{pH}$ was more difficult. While the Resintech phosphonate was able to remove $>95 \%$ of the Ba at a solution-to-solid ratio of 50 , its effectiveness fell off sharply at higher solution-to-solid ratios. While the Biorad sulfonate was not quite as high, it maintained approximately $85 \%$ Ba removal across all solution-to-solid ratios studied.

At $\mathrm{pH}$ 2.5, Mg removal by all four functionalities was quite good; the exception was the Resintech aminophosphonate at a solution-to-solid ratio of 500 (which removed less than half of the Mg from the $\mathrm{D}_{1}$ effluent). Ca removal was good with all four functionalities and solution-to-solid ratios, dipping down to $80 \%$ removal only with the Resintech aminophosphonate at a solution-to-solid ratio of 500 (the other samples were generally $>95 \%$ removal).

The near-neutral pH (i.e., mixed) samples were generally very effectively scavenged for both $\mathrm{Mg}$ and $\mathrm{Ca}$, with moderate success for $\mathrm{Ba}$. Mg was most effectively scavenged at high solution-to-solids ratios (generally $>98 \%$; the exception was Biorad sulfonate at 90\%). Lower solution-to-solid ratios were also successful, but less so. Ca was also removed most effectively at high solution-to-solids ratios (i.e., 500). In this case, all four functionalities were effective at removing $>95 \%$ of the Ca (lower solution-to-solid ratios were once again somewhat less effective). The results were less inconsistent for Ba. Biorad sulfonate was effective at all solution-to-solid ratios ( $>93 \%$ Ba removed). The Sybron diphosphonate functionality was also effective at about $88 \%$ Ba removal. The Resintech aminophosphonate functionality was inconsistent at lower solution-to-solid ratios but was very good at a solution-to-solid ratio of 500 (97\% Ba removed). The Bayer carboxylate functionality was ineffective for all samples.

Integrated over the entire series of tests, the sulfonate functionality was overall the most effective group, with the exception of removing Ca from the alkaline effluent $\left(\mathrm{E}_{\mathrm{op}}\right)$. The second most effective functionality overall was the diphosphonate, but this tended to lose its efficacy at higher solution-to-solid ratios. The carboxylate is effective at removing $\mathrm{Ca}$ and $\mathrm{Mg}$, but not as effective at removing $\mathrm{Ba}$. The phosphonate is very effective at removing $\mathrm{Mg}$ under both acidic and alkaline conditions, and very good at removing $\mathrm{Ca}$ at $\mathrm{pH} 2.5$ and 7.5, but generally ineffective at $\mathrm{pH} 1.8$.

Implementation Design. Due to the high density and rapid kinetics of the SAMMS material developed in the ongoing phase of the project, an up-flow fluidized-bed (UFFB) engineered approach was proposed for possible demonstration. This approach would provide several significant advantages relative to fixed-bed commercial ion exchange including:

1. Minimal Prefiltration. Presently, fixed-bed processes (FBP) require prefiltration down to 1 micron to avoid plugging the bed. The tested filtration systems have shown significant operational issues since the bleach mill process inherently generates high levels of suspended solids. The UFFB approach takes advantage of the high density of the SAMMS by allowing suspended solids to flow through the process without carryover of SAMMS to the treated effluent (Figure 6). This eliminates the single most problematic, operational concern associated with ion exchange processes. 


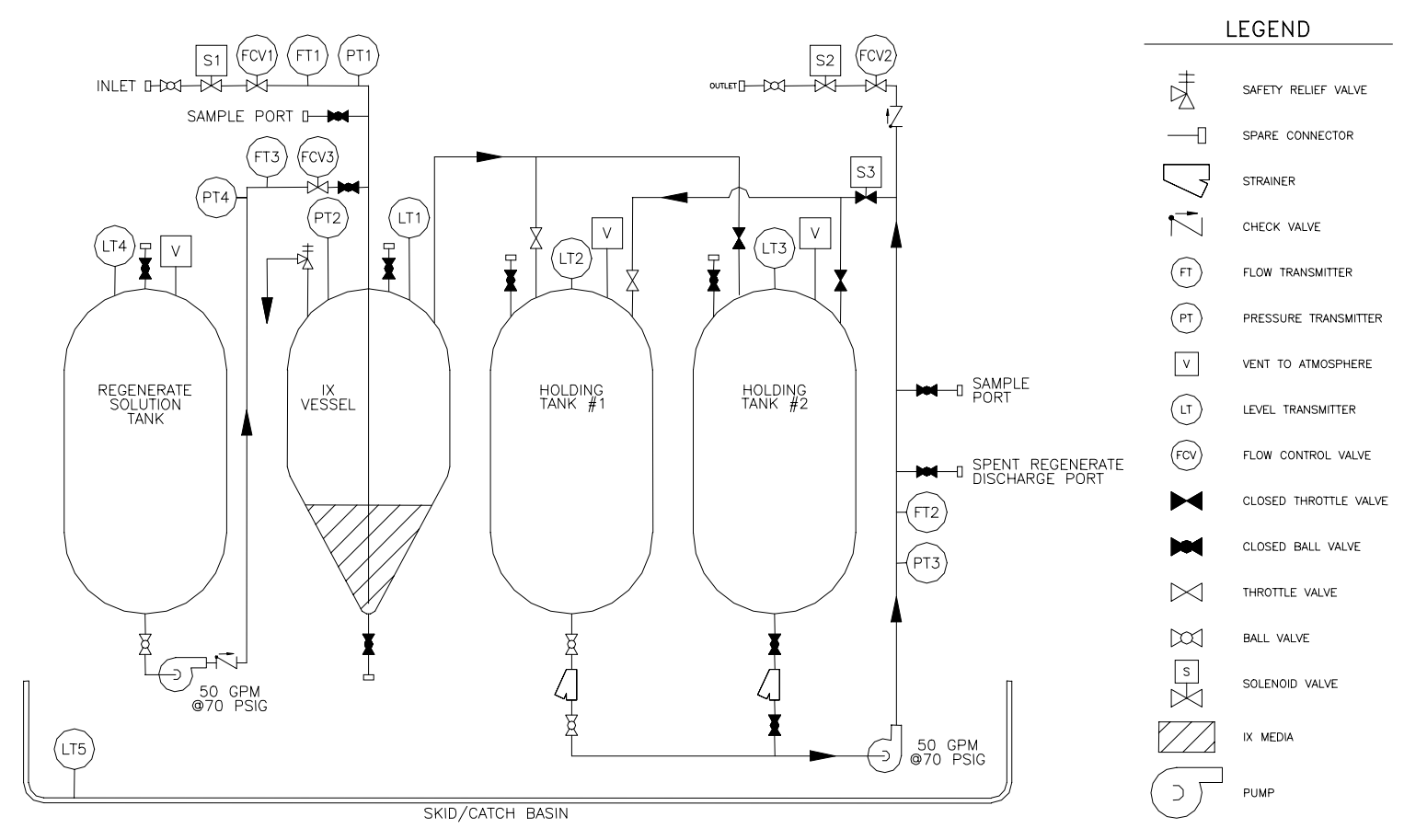

Figure 6. Schematic of UFFB System for Deployment of SAMMS

2. Rapid Kinetics. The rigid, open-pore structure provides rapid sorption capability. This allows for a single-pass removal of NPEs that supports a closed-loop operation.

3. High Capacity. The monolayer structure provides the highest possible loading capacity. This translates into less media and smaller equipment (lower capital cost) for a given size process.

4. Stable Inorganic Backing. This correlates to regeneration capability and lower attrition. During regeneration, organic based ion exchange is subject to swelling and shrinking, which leads to production of fines and loss of media. SAMMS inorganic backing does not shrink or swell (minimal attrition) and has been demonstrated to be regenerated for over 10 cycles with no loss of capacity.

Settling and Abrasion Tests of SAMMS Powder. To determine the suitability of SAMMS in this apparatus, it was necessary to determine both the settling velocity of the SAMMS powders and their ability to withstand the levels of abrasion encountered in this system.

The objectives of these experiments were:

1. To determine the settling velocity of thiol-SAMMS versus flow, and

2. Determine the amount of fines that will be generated when thiol SAMMS is shaken for 48 hours. The material tested was Batch \#7 SAMMS (65 A).

Settling Velocity. In these experiments, a container was prepared with an inlet at the bottom and an overflow outlet at the top (8-cm [3-in.] ID column; distance between inlet and outlet $33 \mathrm{~cm}$ [13 in.]); inlet 
and outlet opening 0.32-cm [1/8-in.] ID). One gram of thiol SAMMS was added to a known volume of deionized (DI) water in the container. The suspension was placed on a stir plate and stirred for 15 minutes, then the stir plate was turned off and the pump started, pumping DI water into the vessel at a rate of $10 \mathrm{~mL} /$ hour. After purging the system with $400 \mathrm{~mL}$ of DI water, a $30-\mathrm{mL}$ sample of the overflow was collected and measured for turbidity. The sample was then dried to determine the amount of total suspended solids (TSS) in the effluent. This experiment was then repeated at flow rates of 20, 30, 50, 75, 100, and $200 \mathrm{~mL} / \mathrm{hr}$. A calibration curve was also generated to correlate the measured turbidity with total suspended solid concentration (Figure 7).

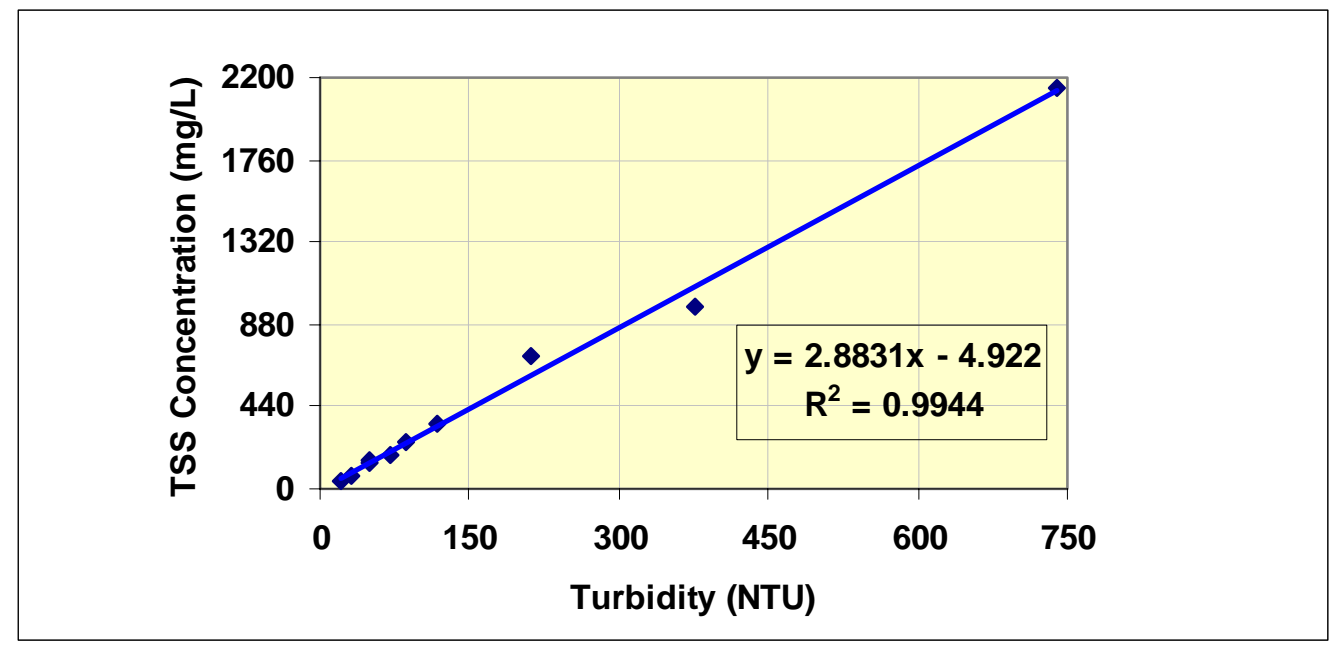

Figure 7. Calibration Curve: Turbidity Versus Total Suspended Solids (TSS)

The turbidity measurements of the effluent at various flow rates (Figure 8) indicated a log-linear relationship between the TSS and the flow rate. The data showed that, depending on the flow rate, effluent contained $\sim 2-6 \%$ of the original mass of material. The results showed that the with appropriate system design and fines recovery, the material could be used in a fluidized bed system.

Abrasion Test. A weighed (approximately 2-gram) sample of Batch\#7 SAMMS powder was placed in each of six tared $250-\mathrm{ml}$ containers, along with $230 \mathrm{~mL}$ of DI water. The bottles were shaken (200 rpm) for 4, 8, 24, 48, 72, and 96 hours. After each time period, a sample bottle was removed from the shaker and allowed to settle on the bench top (7 hours, 5 minutes). A 30-mL aliquot was removed and analyzed for turbidity (to determine the population of $<1 \mu \mathrm{m}$ particles). After measuring the turbidity, the aliquot was dried to determine the solid concentration (in $\mathrm{g} / \mathrm{mL}$ ).

The data showed that before attrition, the material originally contained about $7 \%$ by mass of fine material $(<1 \mu \mathrm{m})$ (Figure 9). The results showed that attrition, on average, generated an additional $3.6 \pm 1.5 \%$ by mass fine material. Also, with increased attrition time there was no significant increase in the mass of fines generated, indicating that the SAMMS material (being silica-based) was relatively resistant to particle breakage when deployed in a fluidized bed. 


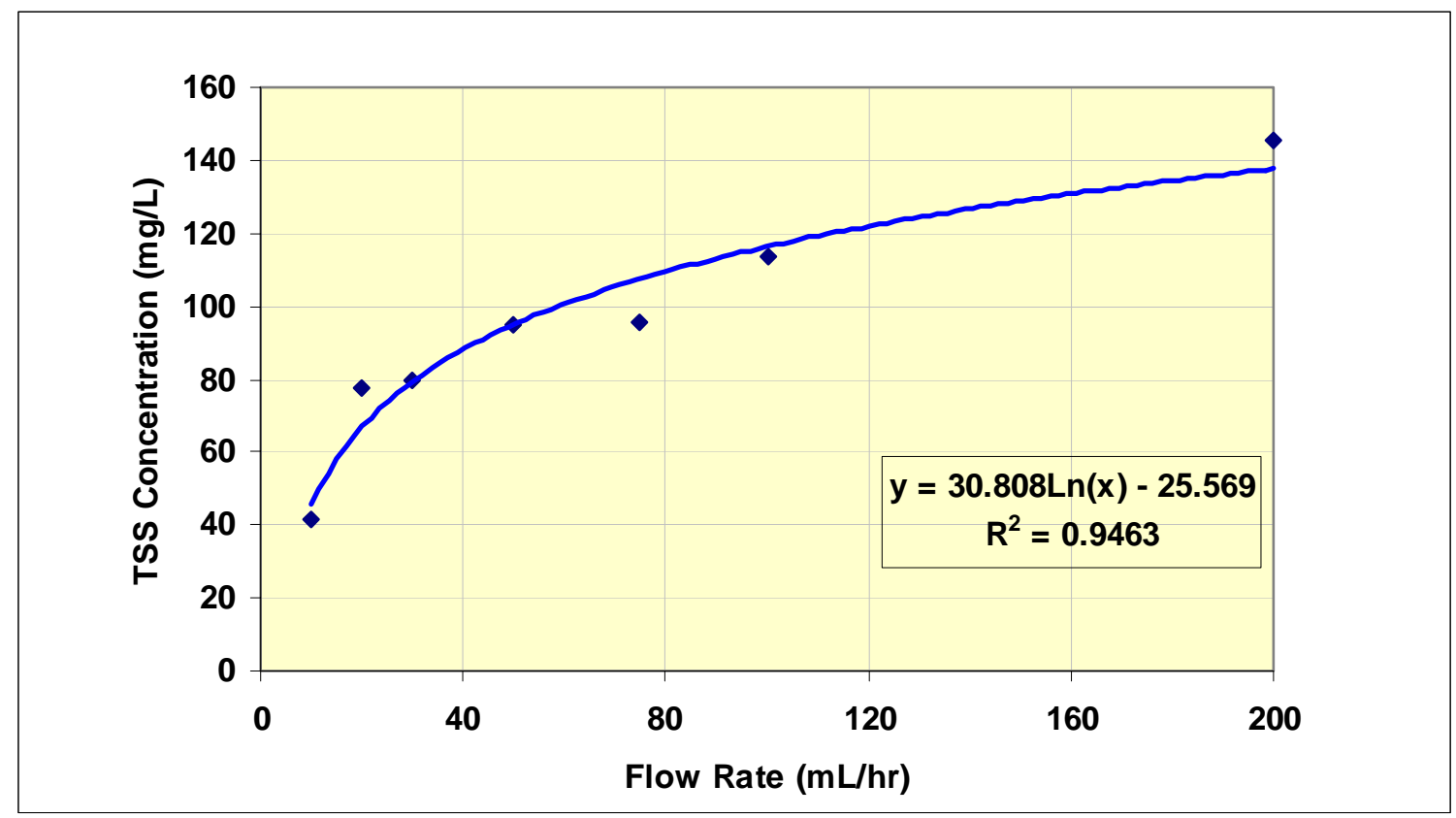

Figure 8. TSS in the Effluent as a Function of Flow Rate

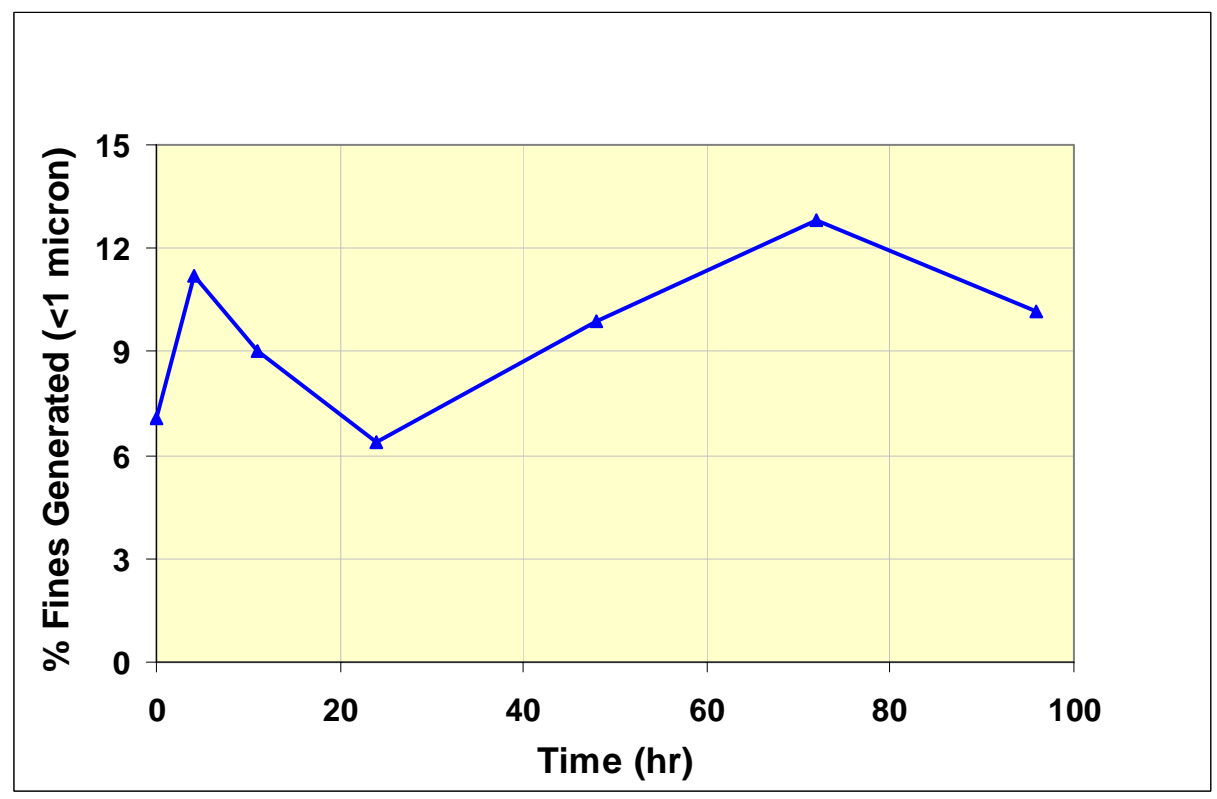

Figure 9. Attrition of Thiol-SAMMS as a Function of Time

Attrition Test of SAMMS Powder. The objectives of this experiment were to determine the amount of $<53 \mu \mathrm{m}$ particles that might be generated when SAMMS sorbent materials are attrited for up to 96 hours. The material tested was Richman Chemical functionalized thiol-SAMMS. This sample was sieved and separated into two different size fractions, $>106 \mu \mathrm{m}$ and $<106$ - $53 \mu \mathrm{m}$. 
A 1-g sample of SAMMS was placed into each of seven 250-mL containers and suspended in $250 \mathrm{~mL}$ of DI water. These samples were shaken (at $200 \mathrm{rpm}$ ) for 0, 4, 8, 24, 48, 72, and 96 hours (the 0 hour sample was shaken briefly by hand to suspend the particles, a $150-\mathrm{mL}$ aliquot was removed by pipet 5.5 $\mathrm{cm}$ below the water surface and analyzed for $<53 \mu \mathrm{m}$ particles). As each sample was removed from the shaker, it was allowed to settle for 23 seconds (to allow all particles of $>53 \mu \mathrm{m}$ to settle), and then a 150$\mathrm{mL}$ aliquot was removed (again, by pipet $5.5 \mathrm{~cm}$ below the surface) to sample the $<53 \mu \mathrm{m}$ particles. The sample was centrifuged, and the solids were transferred to a weigh boat, dried, and weighed to determine the solids concentration (in $\mathrm{g} / \mathrm{mL}$ ).

The results showed that attrition of the fine fraction, on average, generated $\sim 1.5 \%$ by mass of $<53 \mu \mathrm{m}$ material. The mass of the fines generated in this experiment appeared to be relatively independent of the attrition time (Figure 10). However, fines $(<53 \mu \mathrm{m})$ generated from the attrition of the coarse fraction $(>106 \mu \mathrm{m})$ increased linearly with time up to $\sim 30$ hours, after which it remained relatively constant at $\sim 6 \%$ by mass up to 72 hours. There appeared to be an increase in the amount of fines (additional $2.5 \%$ by mass) when the attrition time was extended to 96 hours. The fine fraction appeared to be more resistant to attritive forces as compared to the coarse fraction of SAMMS. Therefore, the $<106>53 \mu \mathrm{m}$ size fraction of SAMMS appears to be the optimum particle size material for use in fluidized bed applications.

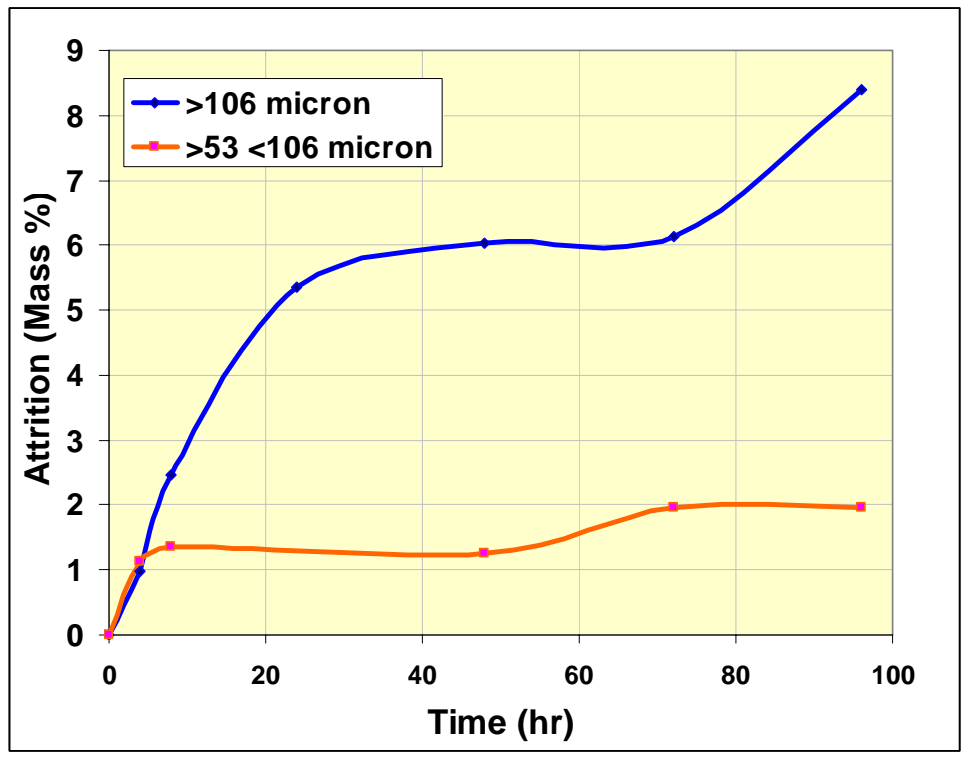

Figure 10. Attrition Test (Mass of fines $<53 \mu \mathrm{m}$ ) of Thiol-SAMMS as a Function of Time

Attempts to improve on this attrition and settling velocity behavior were made by taking the MCM-41 support and tape casting it with a polybutyrate binder in a 0.5-mm tape and calcining for 2 hours at $500^{\circ} \mathrm{C}$. In this way, the average particle size was increased to approximately 400-500 $\mu \mathrm{m}$. However, these agglomerated particles were found to be relatively fragile and broke down to smaller sizes upon continued stirring and/or agitation.

SAMMS Synthesis. Mesoporous silica (MCM-41) with $65 \AA$ pores was made using cetyltrimethylammonium bromide (CTAB) surfactant and mesitylene as a pore expander, under alkaline 
hydrothermal conditions for 1 week, as previously described (Feng et al. 1997). The functional monolayers were either installed in "masked" form and then subsequently modified, or the silanes were constructed first and deposited after elaboration. A brief summary of each synthesis follows. The sulfonic acid SAMMS were made by taking the corresponding thiol-SAMMS and oxidizing the mercaptan using hydrogen peroxide in glacial acetic acid (Figure 11). The phosphonate terminated SAMMS was made by using a CDI mediated coupling reaction between 3-aminopropyltrimethoxysilane (APTMS) and diethylphosphonoacetic acid (as shown in Figure 11). The phosphonate esters were cleaved using TMSI, then exposed to water. The carboxylate SAMMS (Figure 3) were made by treating 3-isocyanatopropyltrimethoxysilane with glycine in the presence of triethylamine. The dicarboxylate SAMMS were made by treating APTMS with two equivalents of ethyl bromoacetate (buffered with triethylamine). The esters were cleaved with TMSI after the silanes were deposited within the MCM-41. The diphosphonate SAMMS (not shown) were prepared by treating tetraethylmethylene diphosphonate with potassium t-butoxide in anhydrous DMF and quenching with 3-chloropropyltriethoxysilane. Once again, the esters were cleaved using TMSI after deposition on the MCM-41.

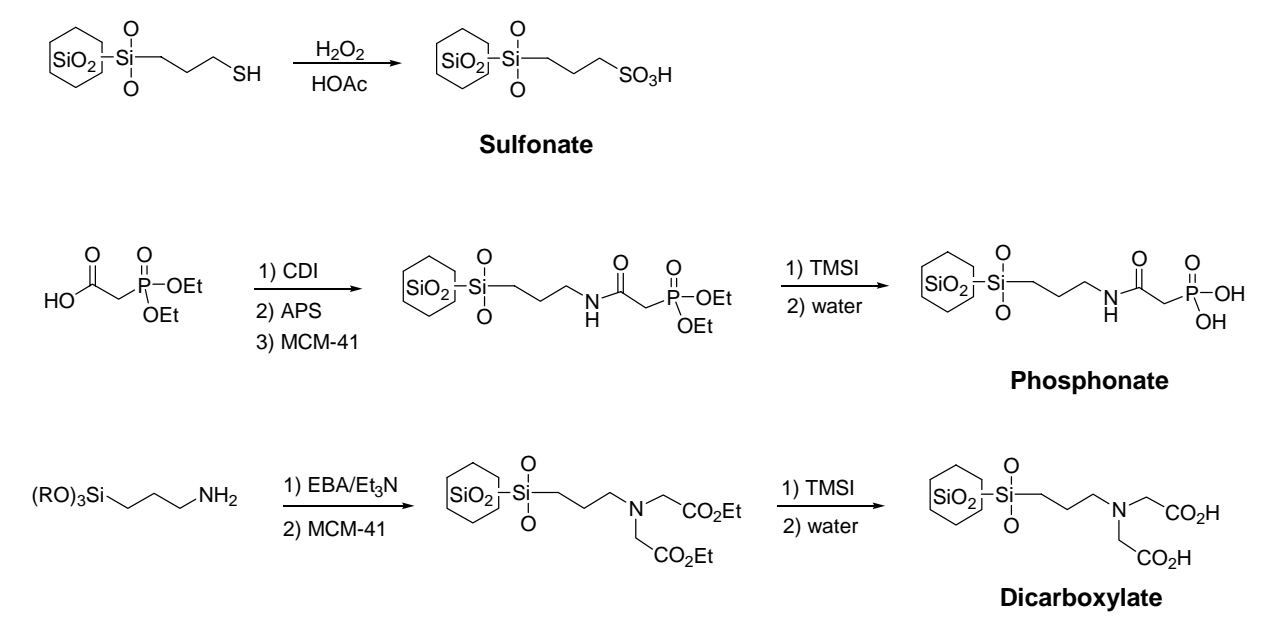

Figure 11. Synthetic Approaches Used to Make Various Functionalities on SAMMS

These deposition methods resulted in a population density ranging from 5 silanes $/ \mathrm{nm}^{2}$ (e.g., the thiol SAMMS) to approximately 1 silane $/ \mathrm{nm}^{2}$ (diphosphonate). Most of the SAMMS described above have population densities on the order of 2-2.5 silanes $/ \mathrm{nm}^{2}$ (as determined by solid state 29-Si NMR). This 
provides a functional density of approximately 2-4 mmoles/g of sorbent material (depending on molecular weight of the particular silane used). This is roughly double that of typical ion exchange resins.

SAMMS Testing. The solution-to-solid ratio was varied from 100 to 10,000 (Table 2). Eight-hour contact times were employed to ensure the samples were completely equilibrated. The test matrix originally involved testing these different functional "flavors" of SAMMS with the different effluents. However, project funding ran out before it was possible to complete this matrix. The data obtained were in good agreement with our previous work evaluating the various ion exchange functionalities for Ca and Mg sequestration (see Functionality Tests section above). For example, the Ca isotherm when using sulfonate SAMMS suggests Langmuirian behavior. At a solution-to-solid ratio of 100 , over $97 \%$ of the Ca was removed from solution (this effluent contained $55 \mathrm{mg} / \mathrm{L} \mathrm{Ca}$ (see Appendix 1 for a more complete composition). Depending on the solid-to-solution ratio, the distribution coefficients (a mass weighted partition coefficient) were found to range from $\sim 800$ to $\sim 3,860 \mathrm{ml} / \mathrm{g}$, indicating good affinity for the target analyte.

Table 2. Distribution Coefficients for Ca Using Sulfonate SAMMS

\begin{tabular}{||c|c|c|c||}
\hline $\begin{array}{c}\text { Solution-to-Solid } \\
\text { Ratio (ml/g) }\end{array}$ & $\begin{array}{c}\text { Eq Conc } \\
(\mathrm{mg} / \mathrm{L})\end{array}$ & $\begin{array}{c}\text { Loading } \\
(\mathrm{mg} / \mathrm{g})\end{array}$ & $\mathrm{K}_{\mathrm{d}}(\mathrm{ml} / \mathrm{g})$ \\
\hline \hline 100 & 1.4 & 5.4 & 3857 \\
\hline 100 & 1.5 & 5.4 & 3600 \\
\hline 500 & 13.9 & 20.6 & 1482 \\
\hline 500 & 16.4 & 19.3 & 1177 \\
\hline 1000 & 25.7 & 29.3 & 1140 \\
\hline 1000 & 24.6 & 30.4 & 1236 \\
\hline 5000 & 47.7 & 36.5 & 765 \\
\hline 5000 & 48.9 & 30.5 & 624 \\
\hline 10000 & 50.7 & 43.0 & 848 \\
\hline 10000 & 50.9 & 41.0 & 806 \\
\hline \hline
\end{tabular}

Sorption Kinetics. Kinetics experiments were carried out using a solution-to-solid ratio of 2000. The SAMMS material was contacted with the Oglethorpe effluent, and the mixtures were shaken with aliquots withdrawn at 0.5, 1, 3, 5, 10, 30, 60 180, 360, and 1440 minutes and analyzed for remaining Ca concentration (Figure 12). As shown in Figure 13, equilibrium is achieved rapidly, in only a few minutes. At longer exposure times, it is also apparent from the data that none of the entrained Ca leaches back out of the laden SAMMS material.

As previously mentioned, the test matrix was not completed because project funding ran out before the testing was completed. However, the data obtained are consistent with the ion exchange resin data compiled and indicate that SAMMS are faster than typical polymer-based IX resins and may have twice as much binding capacity. 


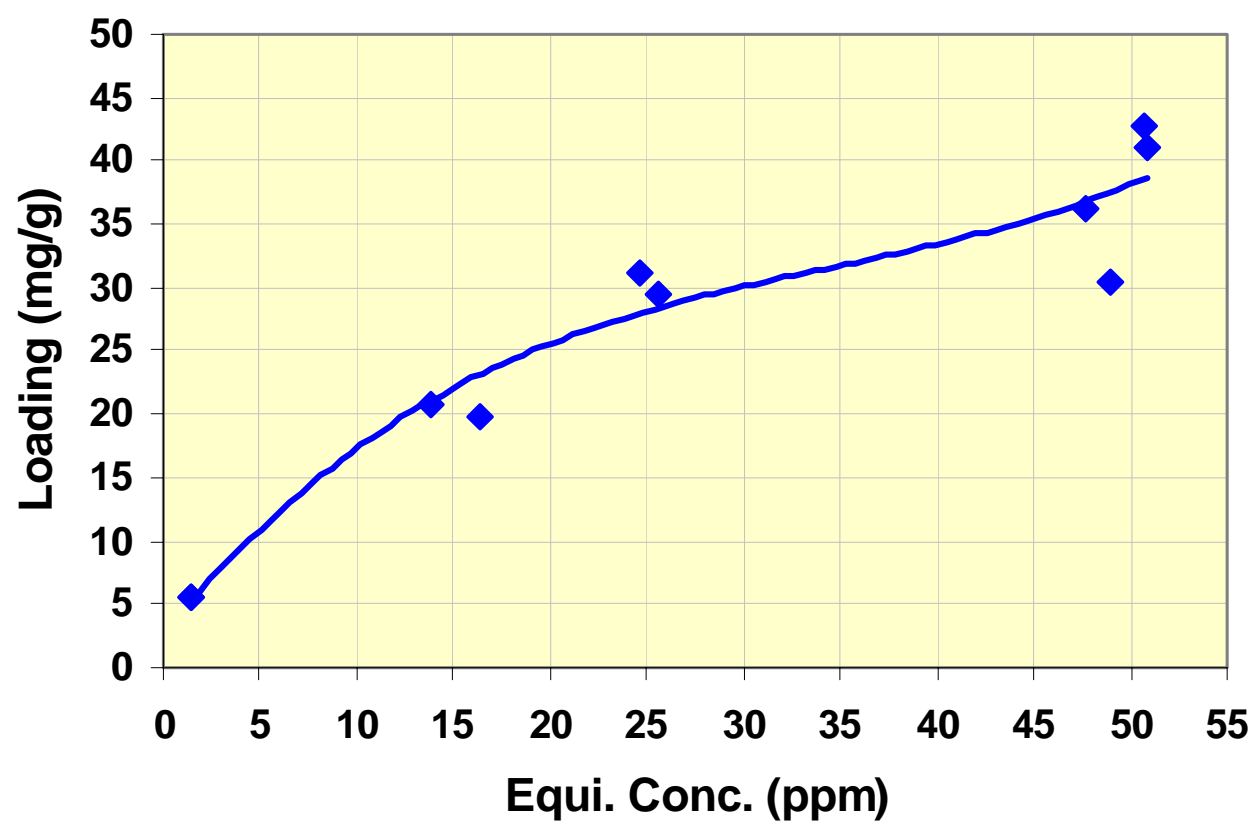

Figure 12. Sorption Isotherm Using Sulfonate SAMMS.

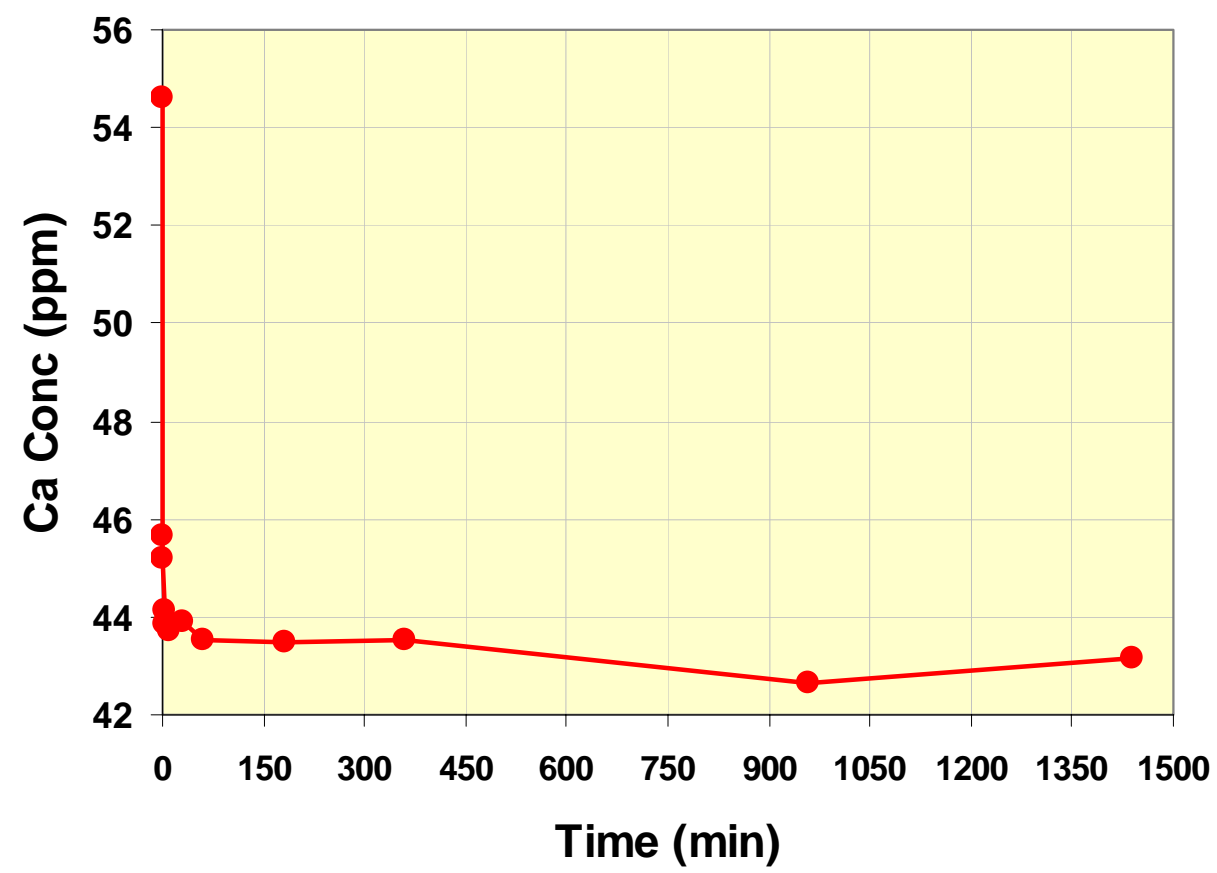

Figure 13. Sorption Kinetics of Ca Using Sulfonate SAMMS. 


\subsection{Conclusions}

In this project we accurately determined the chemical composition of a Weyerhauser bleach plant effluent in the $E_{\mathrm{op}}, \mathrm{D}_{0}$, and $\mathrm{D}_{1}$ stages. Due to environmental regulatory concerns, Mn was the principal target of this study. Mn was found to be present in these samples in the range of 0.16 to $3.97 \mathrm{ppm}$. The Mn was found to be in the divalent oxidation state. Other species of interest were the scale forming cations Ca (21.4 to $161 \mathrm{ppm}$ ) and Mg (1.0 to $20 \mathrm{ppm}$ ); Ba is not likely to be a significant cause of scale in these effluents and is present only in the range of 0.03 to $0.22 \mathrm{ppm}$.

Various methods were evaluated for their ability to remove $\mathrm{Mn}^{+2}$ from these effluents, and carboxylate SAMMS was found to be the most effective sorbent tested. Mesoporous silica and activated alumina were ineffective.

Because of the strongly oxidizing conditions during certain stages of the bleaching process, it was decided to examine the efficacy of SAMM for permanganate $\left(\mathrm{Mn}^{+7}\right)$ removal. Cu-EDA SAMMS have proven to be superior for the sequestration of other tetrahedral oxoanions (e.g., chromate, arsenate, etc.) and so were tested for permanganate and found to be effective, as were EDA SAMMS and EDA-modified IX resins. It appears that permanganate reacts with the EDA ligand, and the oxidized ligand has a very high affinity for the reduced Mn. This redox process was very fast.

To be able to deploy SAMMS in an industrial setting, it was necessary to design a test skid that would allow suitable flow rates with minimal back pressures. It was also important to factor in the need for sorbent bed regeneration. This design was drawn up and incorporated into a truck-portable skid that could be dropped in place and plumbed into the bleach plant for pilot-scale testing and evaluation.

Important factors for the successful application of SAMMS in this test skid were settling velocity and particle size attrition. These measurements were made. Attrition was found to generate fines $(<53 \mu \mathrm{m})$ up to approximately $6 \mathrm{wt} \%$, and then fines generation appeared to level off. The settling velocity testing showed that with appropriate system design and fines recovery, the SAMMS material could be used in the UFFB system.

Extensive testing was carried out to find which functional groups were most effective to bind the scale-forming cations under conditions similar to those encountered in the pulp bleaching process. The sulfonate resin was found to be the most effective overall, except for removing Ca from the alkaline $\mathrm{E}_{\mathrm{op}}$. The diphosphonate was found to be the second most effective overall, but it tended to lose its efficacy at higher solution-to-solid ratios. The carboxylate was effective at removing $\mathrm{Ca}$ and $\mathrm{Mg}$, but not as effective at removing $\mathrm{Ba}$ (which is acceptable since $\mathrm{Ba}$ is the smallest concern in these effluents). The phosphonate resin was found to be very effective at removing Mg under both acidic and alkaline conditions, very good at removing Ca at pH 2.5 and 7.5, but basically ineffective at more acidic pHs.

Tests were carried out to evaluate the sorption kinetics of SAMMS materials for scale-forming cations. Sorption was rapid, and equilibrium was achieved in just a few minutes. Once sorbed, there was no evidence of Ca leaching back out of the sorbent material. 


\subsection{References}

\section{Cited Literature}

Fryxell GE, J Liu, M Gong, TA Hauser, Z Nie, RT Hallen, M Qian, and KF Ferris. 1999. "Design and Synthesis of Selective Mesoporous Anion Traps.” Chemistry of Materials 11:2148-2154.

Feng X, GE Fryxell, LQ Wang, AY Kim, and J Liu. 1997. “Organic Monolayers on Ordered Mesoporous Supports.” J. Science 276:923-926.

\section{Publications}

\section{Book Chapters}

Fryxell GE, and J Liu. 2000. "Designing Surface Chemistry in Mesoporous Silica,” an invited contribution to Adsorption at Silica Surfaces, E Papirer and M Dekker (eds.), pp. 665-688.

Fryxell GE, J Liu, SV Mattigod, LQ Wang, M Gong, TA Hauser, Y Lin, KF Ferris, and X Feng. 2000. "Environmental Applications of Interfacially Modified Mesoporous Ceramics," in Ceramics Transactions, Environmental Issues and Waste Management Technologies in the Ceramic and Nuclear Industries, Volume 107, GT Chandler and X Feng (eds.), pp. 29-37.

Liu J, GE Fryxell, SV Mattigod, TS Zemanian, Y Shin, and LQ Wang. 2000. "Synthesis and Applications of Functionalized Nanoporous Materials for Specific Adsorption,” in Studies in Surface Science and Catalysis, A. Sayari, et al. (eds.), Elsevier, Vol. 129, pp. 729-738.

\section{Peer-Reviewed Journal Articles}

Zemanian TS, GE Fryxell, J Liu, SV Mattigod, JA Franz, and Z Nie. 2001. “Deposition of SelfAssembled Monolayers in Mesoporous Silica from Supercritical Fluids.” Langmuir 17(26):8172-8177.

Kelly S, K Kemner, GS Fryxell, J Liu, SV Mattigod, and KF Ferris. 2001. “An X-Ray Absorption Fine Structure Spectroscopy Determination of the Binding Mechanisms of Tetrahedral Anions to SelfAssembled Monolayers on Mesoporous Supports.” Journal of Synchrotron Radiation 8:922-924.

Kelly S, K Kemner, GS Fryxell, J Liu, SV Mattigod, and KF Ferris. 2001. "X-Ray Absorption Fine Structure Spectroscopy Study of the Interactions Between Contaminant Tetrahedral Anions to SelfAssembled Monolayers on Mesoporous Supports.” Journal of Physical Chemistry 105:6337-6346.

Liu J, GE Fryxell, M Qian, L-Q Wang, and Y Wang. 2000. "Interfacial Chemistry in Self-Assembled Nanoscale Materials with Structural Ordering," an invited contribution to Pure and Applied Chemistry 72:269-279. 
Shin Y, J Liu, L-Q Wang, Z Nie, WD Samuels, GE Fryxell, and GJ Exarhos. 2000. “Ordered Hierarchical Porous Materials: Towards Tunable Size-and-Shape Selective Microcavities in Nanoporous Channels.” Ang. Chem. Int. Eng. Ed. 39:2702-2707.

Fryxell GE, J Liu, M Gong, TA Hauser, Z Nie, RT Hallen, M Qian, and KF Ferris. 1999. "Design and Synthesis of Selective Mesoporous Anion Traps.” Chemistry of Materials 11:2148-2154.

\section{Presentations}

Fryxell GE, SV Mattigod, RL Leugemors, M Paster, V Robinson, D Biancosino, and H Persinger. 2001. "Non-Process Element (NPE) Removal Using Functionalized Monolayers on Mesoporous Supports," AF\&PA Headquarters, Washington, D.C., May 6, 2001.

Fryxell GE. 2001. “Using Molecular Self-Assembly for Environmental Clean-up Applications,” invited contribution to University of Washington Workshop on Nanoscale Science and Technology, Seattle, August 16-17, 2001.

Smith M, D Biancosino, J Liu, S Baskaran, GE Fryxell, SV Mattigod, H Wu, J Virden, K Holman, P Wollwage, H Persinger, Q Pu, B Loew, A Chavez, A Ono, and A Ramos. 2000. "Non-Process Element (NPE) Removal Using Mesoporous Supports,” AF\&PA Headquarters, Washington, D.C., June 6-7, 2000.

Fryxell GE, J Liu, SV Mattigod, LQ Wang, M Gong, TA Hauser, Y Lin, KF Ferris, and X Feng. 1999. "Environmental Applications of Interfacially Modified Mesoporous Ceramics," presented as a part of Symposium H: Science and Technology Addressing Environmental Issues in the Ceramic Industry, $101^{\text {st }}$ National Meeting of the American Ceramic Society, Indianapolis, April 1999. 


\section{Appendix 1}

\section{Oglethorpe Waste Composition}


Table A.1. Oglethorpe Waste Composition

\begin{tabular}{||c|r|c|r||}
\hline Constituent & $\mathrm{mg} / \mathrm{L}$ & Constituent & $\mathrm{mg} / \mathrm{L}$ \\
\hline \hline $\mathrm{Al}$ & 1.21 & $\mathrm{~K}$ & 7.78 \\
\hline $\mathrm{B}$ & 0.04 & $\mathrm{Mg}$ & 13.74 \\
\hline $\mathrm{Ba}$ & 0.33 & $\mathrm{Mn}$ & 3.14 \\
\hline $\mathrm{Br}$ & $<1.00$ & $\mathrm{Mo}$ & 0.02 \\
\hline $\mathrm{Ca}$ & 55.00 & $\mathrm{Na}$ & 469.60 \\
\hline $\mathrm{Cd}$ & 0.01 & $\mathrm{Ni}$ & 0.02 \\
\hline $\mathrm{Cl}$ & 669.50 & $\mathrm{NO}_{2}$ & $<1.00$ \\
\hline $\mathrm{ClO}_{3}$ & 460.80 & $\mathrm{NO}_{3}$ & 4.48 \\
\hline $\mathrm{C}_{2} \mathrm{O}_{4}$ & 9.98 & $\mathrm{PO}_{4}$ & 9.80 \\
\hline $\mathrm{CHO}_{2}$ & 122.70 & $\mathrm{~Pb}$ & 0.02 \\
\hline $\mathrm{C}_{2} \mathrm{H}_{3} \mathrm{O}_{2}$ & 108.50 & $\mathrm{Si}$ & 16.04 \\
\hline $\mathrm{Cr}$ & 0.03 & $\mathrm{SO}_{3}$ & 3.00 \\
\hline $\mathrm{Cu}$ & 0.02 & $\mathrm{SO}_{4}$ & 46.5 \\
\hline $\mathrm{Fe}$ & 0.52 & $\mathrm{Sr}$ & 0.20 \\
\hline $\mathrm{F}$ & 6.48 & $\mathrm{Zn}$ & 1.71 \\
\hline \hline
\end{tabular}

A.1 